LIÉBANA ORTIZ, J.R., «Argumentos de Derecho comparado para extender las tasas judiciales al orden social», REDUR I5, diciembre 20I7, págs. 29-55. ISSN I695-078X

\title{
ARGUMENTOS DE DERECHO COMPARADO PARA EXTENDER LAS TASAS JUDICIALES AL ORDEN SOCIAL
}

\author{
Juan Ramón LIÉBANA ORTIZ \\ PROFESOR ADJUNTO DE DERECHO PROCESAL \\ UNIVERSIDAD INTERNACIONAL DE LA RIOJA
}

SumARIO: I. De la pretendida privatización de la justicia a través de diversos métodos. II. Una aproximación europea a las tasas judiciales. III. Las tasas judiciales en los ordenamientos jurídicos español y británico. III.I. En el ordenamiento jurídico español. III.I.I. Hecho imponible y cuota tributaria. III.r.2. Tasas judiciales y tutela judicial efectiva. III.I.3. La anulación (parcial) de las tasas judiciales. III.2. En el ordenamiento jurídico inglés. III.2.I. Las tasas judiciales en general. III.2.2. Las tasas judiciales en el orden social. III.2.3. Tasas judiciales en el orden social y tutela judicial efectiva. III.2.4. La reforma de las tasas judiciales. IV. En favor de las tasas judiciales en el orden jurisdiccional social. IV.r. Identificación de la problemática. IV.2. Los beneficios de las tasas judiciales en el orden social. V. Conclusiones.

RESUMEN: El presente trabajo analiza la semejanza de la regulación legal de las tasas judiciales en los ordenamientos jurídicos español e inglés, con especial referencia al orden jurisdiccional laboral, teniendo como referencia fundamental los pronunciamientos del Tribunal Europeo de Derechos Humanos y el Tribunal de Justicia de la Unión Europea. El trabajo constata que enfrentan las mismas críticas desde al menos el siglo XVIII, y que los pronunciamientos jurisdiccionales nacionales son también muy similares. Utilizando argumentos de Derecho comparado, el trabajo concluye con una defensa de las ventajas de extender las tasas judiciales al orden jurisdiccional social.

Palabras Clave: tasas judiciales, Derecho a la tutela judicial efectiva, Jurisprudencia europea, Orden jurisdiccional social, Derecho español, Derecho inglés

AbSTRACT: This essay analyzes the similarity of the court fees' legal regime in both the Spanish and the English legal systems, with a special reference to the Employment Tribunal fees, having as a framework the European Court of Human Rights and the Court of Justice of the European Union case law. The essay points out that court fees face the same criticisms from at least the eighteenth century, and that national judgements regarding court fees are also very similar. Using arguments of comparative law, the essay concludes with a defense of the advantages of extending the court fess to the Employment Tribunals.

KEYwORDs: Court fees, Right to access to Justice, European case-Law, Employment Tribunals, Spanish Law, English Law. 


\section{De la pretendida privatización de la justicia a través de diversos métodos}

La conjunción de diferentes intereses sociopolíticos y corporativos diversos respecto de las importantísimas reformas legislativas habidas en España durante su décima Legislatura han conducido a que haya cuajado en la opinión pública la idea de que se intenta privatizar la justicia.

En efecto, la aprobación en dicha legislatura de la Ley de Mediación en Asuntos Civiles y Mercantiles, la Ley por la que se regulan determinadas tasas en el ámbito de la Administración de Justicia y la reforma de la jurisdicción voluntaria ${ }^{\mathrm{r}}$ hizo que se comenzara a hablar en ámbitos jurídicos y periodísticos de la llamada privatización de la justicia civil².

Ya hemos sostenido en otra parte que, como tampoco lo es la regulación de la mediación civil y mercantil en España. En nuestra opinión, la expresión «privatización de la justicia» resulta errónea ya que en rigor no existe. Como hemos sostenido en otra parte ${ }^{3}$, la desjudicialización del Derecho civil y mercantil que impone la Ley de Jurisdicción Voluntaria no implica una privatización de la justicia civil por cuanto el conocimiento de los expedientes de esta clase se encomienda a funcionarios públicos. Por su parte, los sistemas alternativos de solución de conflictos jurídico-privados (i. e., en la mediación y en el arbitraje), en los que el tercero que resuelve el conflicto no es funcionario público, son métodos de adhesión voluntaria de las partes, por lo que siempre está expedita la vía jurisdiccional, y se configuran como herramientas jurídicas adicionales a disposición de los particulares. Además, la ley de mediación civil y mercantil está en línea con las regulaciones de los países de nuestro entorno4, al igual que ocurre con la ley de la jurisdicción voluntarias.

\footnotetext{
${ }^{1}$ En materia de Justicia la décima Legislatura española, transcurrida entre el I3 de diciembre de 20 II y el I2 de enero de 2016 , comenzó con la intención expresa del ministro del ramo de llevar a cabo una modificación estructural de nuestra Administración de Justicia para lograr la eficiencia en la propia Administración de Justicia. De todas las reformas procesales acometidas, resultaron especialmente criticadas la Ley 13/2015, de 24 de junio, de Reforma de la Ley Hipotecaria aprobada por Decreto de 8 de febrero de 1946 y del texto refundido de la Ley de Catastro Inmobiliario, aprobado por Real Decreto Legislativo I/2004, de 5 de marzo; la Ley 15/2015, de 2 de julio, de la Jurisdicción Voluntaria; la Ley I9/2015, de I3 de julio, de medidas de reforma administrativa en el ámbito de la Administración de Justicia y del Registro Civil; la Ley Orgánica 7/2015, de 2I de julio, por la que se modifica la Ley Orgánica 6/1985, de I de julio, del Poder Judicial; y la Ley 42/20I5, de 5 de octubre, de reforma de la Ley I/2000, de 7 de enero, de Enjuiciamiento Civil; por entenderse que al amparo de la llamada jurisdicción voluntaria se trataba de privatizar la justicia. A este respecto, y sin ánimo de exhaustividad, pueden consultarse LiÉBANA ORTIZ, J. R. Y PÉREZ EsCAlona, S., Comentarios a la Ley de Jurisdicción Voluntaria, Thomson Reuters-Aranzadi, Cizur Menor 2OI5; BARRIO DEL Olmo, C. P. (Coord.), Jurisdicción voluntaria notarial, Thomson Reuters-Aranzadi, Cizur Menor 20I5; y LIÉBANA Ortiz, J. R. y Santos del VAlLe, L. F., Las subastas electrónicas, Thomson Reuters-Aranzadi, Cizur Menor $20 \mathrm{O} 6$.
}

${ }^{2}$ Puede consultarse un estudio comparado del impacto que las tasas judiciales tienen en el efectivo acceso a la Justicia de ciudadanos y empresas, así como de la correlativa potenciación de la mediación como medio extrajurisdiccional de solución de conflictos, en los ordenamientos jurídicos de España y Reino Unido en LiÉBANA ORTIZ, J. R., «El fenómeno de la privatización de la justicia a través de las alternativas a la jurisdicción. Una visión comparada de España y Reino Unido», en Aliste Santos, T. J. y López Huguet, M. L. (Coord.), La globalización jurídica, Ed. Atelier, Barcelona 20I7, pp. 409-443

3 Cfr. Liébana Ortiz, J. R. y Sobrino GonzÁlez, T., «Apuntes críticos sobre el Anteproyecto de Ley de Jurisdicción Voluntaria», Revista General de Derecho Procesal, núm.34, 20I4, pp.I-I7.

${ }^{4}$ En Europa la necesidad de combatir la lentitud de la Justicia civil y de reducir los gastos que conllevan los procesos jurisdiccionales no se reconoció formalmente hasta principios del siglo XXI. Así, mediante la 
Por su parte, y a pensar de no suponer novedad alguna en nuestro Derecho ${ }^{6}$, la Ley de tasas judiciales de 2012 ha sido una de las que han generado un rechazo más intenso y generalizado en los últimos tiempos, especialmente en el mundo de la abogacía. Así, mientras que la doctrina ha considerado que su regulación legal era no sólo inoportuna sino también

Recomendación Io/2002, de I8 de septiembre, del Comité de Ministros a los Estados Miembros sobre mediación civil, el Consejo de Europa alentó a los Estados miembros a que regularan el procedimiento de mediación dentro de sus respectivos ordenamientos jurídicos. Posteriormente, en 2004 la Dirección de Justicia e Interior de la Comisión Europea adoptó en 2004 un Código de Conducta para los Servicios Europeos de Mediación, así como una propuesta de legislación para asegurar una práctica y normas uniformes en este ámbito. Ello desembocó en la aprobación de la Directiva 2008/52/CE, del Parlamento Europeo y del Consejo, de 2 I de mayo de 2008, sobre ciertos aspectos de la mediación en asuntos civiles y mercantiles, que proporciona un marco común para la mediación transfronteriza y que obligó a los Estados miembros a que regularan la mediación en materia civil y mercantil en sus respectivos ordenamientos jurídicos antes del 20 de mayo de 201 . Esta Directiva europea introdujo cinco cuestiones básicas en los ordenamientos europeos: cada Estado miembro debe fomentar la formación de mediadores y asegurar que las mediaciones se realizan con las garantías jurídicas adecuadas; los jueces deben poder invitar a las partes en litigio a resolver la controversia a través de una mediación si así lo considera oportuno de acuerdo con las circunstancias de cada caso; los acuerdos de mediación deben ser ejecutables si ambas partes lo solicitan, ya mediante un acuerdo judicial o mediante elevación del acuerdo a escritura pública notarial; la mediación debe llevarse a cabo respetando la confidencialidad de las partes, respetando el secreto profesional del mediador incluso en sede jurisdiccional; y las partes mantiene su derecho a la tutela judicial efectiva incluso aunque hayan sometido la controversia a mediación, siendo que los plazos para la interposición de la demanda se suspenden mientras dure la mediación. En la actualidad los 28 Estados miembros de la Unión Europea han transpuesto dicha Directiva a sus respectivos ordenamientos jurídicos, por lo que el régimen jurídico de la mediación civil y mercantil es similar en todos ellos. Para una visión general al respecto, cfr. HoPT, K. J. y STEFFEK, F., Mediation: Principles and regulation in a comparative perspective, Oxford University Press, Oxford 2012; Esplugues, C., Iglesias, J. L. y Palao, G., Civil and Commercial Mediation in Europe, Vol I y II, Intersentia, Cambridge 2013 y 2014.

${ }^{5}$ Aunque el ámbito de aplicación y los procedimientos que se incluyen dentro de la llamada jurisdicción voluntaria varían mucho en los diversos Estados integrantes de la Unión Europea o el Consejo de Europa, en general puede sostenerse que en ella se incluyen los supuestos en que se produce la intervención de un Juez u otro funcionario público para que los particulares o las empresas puedan satisfacer efectivamente sus intereses privados (así, por ejemplo, LIÉBANA OrTIZ, J. R., Fundamentos dogmáticos de la jurisdicción voluntaria, Iustel, Madrid 20I2, p. I70), si bien también se observa que con carácter general su regulación resulta fragmentaria y confusa. Al igual que ha ocurrido en 2015 con la nueva legislación española sobre esta institución, la tendencia del Derecho procesal europeo en materia de jurisdicción voluntaria es la desjudicialización de determinados expedientes en favor de Secretarios Judiciales, Notarios y Registradores, tal y como ha ocurrido desde el año 2009 en países como Francia y Portugal (para los divorcios de mutuo acuerdo) o Hungría y Eslovenia. Cfr., por todos, Argounov, A. A. (Ed.), Voluntary (non-contentious) jurisdiction around the world, Городец, Моscow 20I7, pp. I4-I86.

${ }^{6}$ Baste recordar, en este sentido, que en el ordenamiento jurídico español las referencias más lejanas que se tienen del concepto de tasa judicial se hacen con la mención al arancel judicial como fórmula de regular el coste de las actuaciones judiciales. Ya en el Ordenamiento de Alcalá (I348) y en la Novísima Recopilación (I805) aparecen disposiciones en este sentido. Ahora bien, el primer arancel judicial general entró en vigor en España el 3 de febrero de 1838 , y desde entonces no ha parado de sufrir modificaciones y derogaciones hasta nuestros días. Cabe destacar, por su proximidad, el Decreto I053/I959, de I8 de junio, por el que se convalida y regula la exacción de tasas judiciales, que establecía un sistema de tasas cuyas cuantías se determinaban con arreglo a un baremo muy detallado, en el que fundamentalmente se atendía al tipo de procedimiento judicial de que se tratara y a la cuantía del litigio; Decreto que fue derogado por la Ley 25/1986, de 24 de diciembre, de supresión de las tasas judiciales. Las tasas reaparecieron en nuestro ordenamiento jurídico en virtud del artículo 35 de la Ley 53/2002, de 30 de diciembre, de medidas fiscales, administrativas y del orden social; aunque lo hicieron de manera limitada, porque sólo habían de satisfacerse en los órdenes jurisdiccionales civil y contencioso-administrativo, y porque sólo estaban obligadas a su pago las personas jurídicas o entidades sin personalidad jurídica con ánimo de lucro que promovieran el correspondiente proceso y cuyo volumen de facturación superase varios millones de euros. Para un análisis en mayor profundidad sobre la evolución legislativa de las tasas judiciales vid., por ejemplo, Glover, H., «Tasas Judiciales», Procuradores, núm. 45, abril 2003 pp. 46-48; Doménech PAscual, G., «Las tasas judiciales a juicio», Indret, núm. I, 20I7, pp. 5-6. 
inconstitucional", la lucha contra las tasas judiciales trascendió el ámbito jurídico para desarrollarse también en los medios de comunicación y en las redes sociales, en donde, gracias a la acción de la auto denominada brigada tuitera, curiosamente también se equipararon con una pretendida privatización de la justicia, ecuación que ha resultado especialmente eficaz como eslogan y arma arrojadiza en el Parlamento y en los Juzgados y Tribunales.

Así las cosas, cabe preguntarse si se trataba de una regulación «injusta como pocas en nuestra reciente historia democrática, que inhabilitaba a nuestro Estado de Derecho [y] devaluaba por completo el contenido de eso que llamamos ciudadanía», hasta el punto de resultar una rara avis entre los países de la Unión Europea, o si, por el contrario, la Ley de tasas judiciales se enmarcaba en las corrientes actuales del Derecho procesal europeo (infra 2).

Puesto que un análisis en profundidad de las tasas judiciales en Europa excede con mucho nuestra capacidad, y probablemente la extensión recomendable para un trabajo como el presente, vamos a centrarnos en el estudio comparado del impacto que las tasas judiciales tienen en el efectivo acceso a la Justicia de ciudadanos y empresas, en los ordenamientos jurídicos de España y Reino Unido9 (infra 3), con especial referencia a las tasas judiciales en el orden social.

\footnotetext{
${ }^{7}$ YÁÑEZ DE ANDRÉs, A., «Las nuevas tasas judiciales: obstrucción a la Justicia», Diario La Ley, núm. 7846, 20I3, p. I; Asencio Mellado, J. M., «La inconstitucionalidad de la Ley de Tasas Io/20I2, de 20 de noviembre», Diario La Ley, núm. 8II5, 20I3, p. I; BeLtrán AguiRRE, J. L., «Las nuevas tasas judiciales y los derechos fundamentales a la tutela judicial efectiva y a la igualdad en la ley», Revista Aranzadi Doctrinal, núm. IO, 20I3, pp. 33-46; Gimeno SENDRA, V., «Acerca de la constitucionalidad de la Ley de tasas judiciales», Revista General de Derecho Procesal, núm. 29, 2013; Molins García-Atence, J., «Las nuevas tasas judiciales», Diario La Ley, núm. 8023, 20I3, p. i; Pérez Bustamante, D., «Análisis sobre la adecuación de las tasas judiciales a los principios constitucionales tributarios», Quincena Fiscal Aranzadi, núm. 9, 20I3; GonzÁlez LóPEZ, J. J., «Tasas y tutela judicial efectiva», Revista Vasca de Derecho Procesal Y Arbitraje, Vol. 25, núm. 3, 20I3, pp. 277-295; RuIZ GonZÁleZ, M. A., «La inconstitucionalidad de las tasas judiciales introducidas por la Ley Io/20I2, de 20 de noviembre», Diario La Ley, núm. 8025, 20I3, p. I; CASANOVAS ORTIZ, I. y MARTín Queralt, J., «La tasa por el ejercicio de la potestad jurisdiccional en los órdenes civil, contenciosoadministrativo y social», Tribuna Fiscal, núm. 269, 20I3; GonZÁlEZ Alonso, A., «Las tasas judiciales (o sobre la aflicción) desde la perspectiva constitucional», Revista Jurídica de la Universidad Autónoma de Madrid, núm. 27, 2013, pp. I57-I82; MARTíneZ SÁNCHEZ, C., «Una aproximación crítica a las tasas judiciales desde el Derecho financiero y tributario», Revista Jurídica de la Universidad Autónoma de Madrid, núm. 27, 20I3, pp. 205-22I; PIÑA GARRIDO, L., «Las polémicas tasas judiciales», Revista Técnica Tributaria, núm. I03, 20I3, pp. IO9-I50; RuIz Garijo, M., «La banalidad de las tasas judiciales: una nueva fractura del Estado del bienestar», núm. 4, 20I3, pp. 9-40; VIÑUELAS Zahinos, M. T., «Tasas judiciales y Derecho comunitario», Revista Doctrinal Aranzadi Social, núm. I6, 2013; Banacloche Palao, J., «El derecho de los ciudadanos a acceder a la justicia: tasa judicial y tutela efectiva», en Soriano García, J. E. (Dir.), Por el Derecho y la libertad. Libro homenaje al Profesor Juan Antonio Santamaría Pastor, Vol. I, Iustel, Madrid 20I4, pp. 342-37I; CierCo SeIrA, C., «Pagar por recibir justicia y el difícil camino de batallar judicialmente contra la Administración», Revista Española de Derecho Administrativo, núm. 165, 20I4, pp. I3-28; SÁnChez ÁlvareZ, E., «Las nuevas tasas judiciales y sus consecuencias en la tutela judicial efectiva», Revista CEF Legal, núm. I57, 20I4, pp. I27-I70; DE LA FuENTE GARRIDO, D., «El obstáculo de las tasas judiciales en la jurisdicción contencioso-administrativa», Revista Jurídica de Catalunya, núm. I, 20I5, pp. I3I-I48; De Prada RodríGUEZ, M., «El acceso a la justicia y las tasas judiciales», Actualidad Civil, núm. 2, 20I5; SÁNCHEz ÁlvAREZ, E., «Un enjuiciamiento constitucional del actual modelo de tasas judiciales. Motivos para su inconstitucionalidad a pesar de las sucesivas atemperaciones legislativas», Revista CEF Legal, núm. I8I, 20I6, pp. III-I50.
}

${ }^{8}$ Cfr. Ibarra SÁnchez, J. L., «El Tribunal Constitucional tumba, por unanimidad, la Ley de tasas», Revista Aranzadi Doctrinal, núm. 9, 2016.

${ }^{9}$ La elección del Reino Unido como ordenamiento jurídico objeto de estudio no es baladí, sino que responde a que se trata del único país regido por el sistema del common law perteneciente (al menos en el momento de escribir estas líneas) a la Unión Europea, siendo además un ordenamiento jurídico tractor tanto para el Parlamento Europeo 
Por último, tras el análisis de la última jurisprudencia española y británica en materia de tasas judiciales, realizaremos una exposición de las razones por las que consideramos que es preciso extender las tasas judiciales con carácter general al orden social con carácter general.

\section{Una aproximación europea a las tasas judiciales}

Las tasas judiciales no se recaudan exclusivamente en España ${ }^{\mathrm{Io}}$. Por el contrario, como se muestra en el siguiente gráfico, resultan marginales los Estados miembro del Consejo de Europa que carecen de tasas judiciales ${ }^{\mathrm{II}}$.

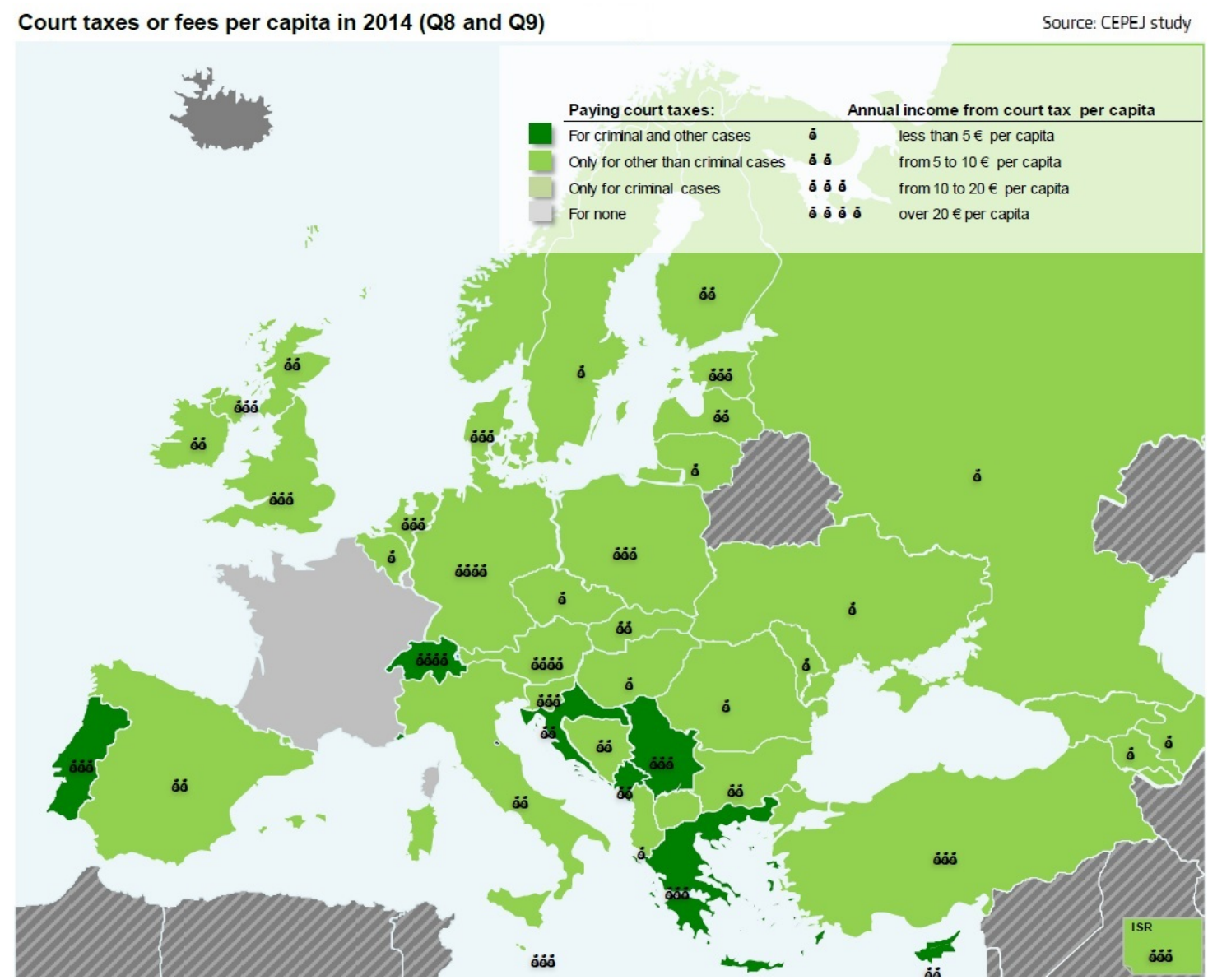

como para la Comisión Europea; es decir, se trata de uno de los ordenamientos jurídicos de referencia en la elaboración de la normativa comunitaria. En este sentido, cfr. Aliste Santos, T. J., Sistema de common law, Ratio legis, Salamanca 20I3; Cuñado de CASTRo, F. y GÁmez GonZÁlez, R., Introducción al common law, Thomson ReutersAranzadi, Cizur Menor 2017.

ro Cfr. Hodges, C., Vogenauer, S. y Tulibacka, M., The costs and funding of civil litigation: a comparative perspective, Hart Publishing, 20I0, passim.

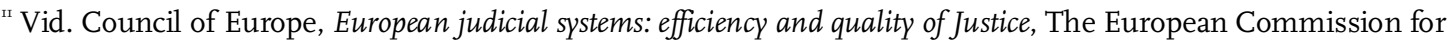
the Efficiency of Justice, Strasbourg 2016, pp. 59-64. 
En efecto, conviene señalar que sólo dos países tienen previsto el acceso gratuito a todas las jurisdicciones en todos los casos: Luxemburgo y Francia ${ }^{\mathrm{I}}$. Por otra parte, con carácter general tampoco se exigen tasas judiciales para el acceso a la justicia penal, salvo en Croacia, Chipre, Grecia, Mónaco, Montenegro, Serbia, Portugal y Suiza, en donde sí está prevista su exacción. Ahora bien, en la mayoría de los Estados en donde se exigen tasas judiciales, la recaudación por este impuesto no se destina al pago de los costes asociados a la impartición de la justicia, sino que se suma a los presupuestos generales de los Estados o de las Regiones, en su caso.

No obstante, los ingresos por tasas judiciales tienen diferentes niveles de impacto en el presupuesto. Por ejemplo, mientras que los Presupuestos Generales de Francia y Luxemburgo soportan íntegramente el gasto en justicia, Austria financia íntegramente el coste de la administración de la justicia vía tasas judiciales. En Bosnia y Herzegovina, Malta y Reino Unido e Irlanda del Norte los ingresos procedentes de las tasas judiciales representan más de la mitad del presupuesto destinado a justicia. Las tasas judiciales también representan casi la mitad del presupuesto total destinado a justicia en Serbia y en Turquía. Por lo que respecta a España, la recaudación por tasas judiciales representó el 8,86\% del total del presupuesto dedicado al sistema judicial, porcentaje que en 2014 cayó hasta el $7 \%{ }^{13}$.

En consecuencia, la práctica totalidad de los países europeos han dispuesto la exacción de tasas judiciales como requisito procesal para el acceso a la justicia. De hecho, la Agencia de los Derechos Fundamentales de la Unión Europea y el Consejo de Europa han señalado que las tasas judiciales pueden contribuir a una administración eficiencia de la justicia ${ }^{\text {I4 }}$, sirviendo por ejemplo para reducir los costes administrativos o como disuasión para los litigantes abusivos.

Por consiguiente, la verdadera cuestión problemática sobre la exacción de tasas judiciales no es su exigencia sino si su configuración legal puede suponer una vulneración de la tutela judicial efectiva. También en este sentido han sido muy claros la Agencia de los Derechos Fundamentales de la Unión Europea y el Consejo de Europa cuando señalan que las tasas judiciales no son automáticamente incompatibles con el art. 6.I del Convenio Europeo de Derechos Humanos o con el art. 47 de la Carta de los Derechos Fundamentales de la Unión Europea (o del art. $24 \mathrm{CE}$, añadimos nosotros). Pero si las tasas judiciales son demasiado elevadas, pueden privar al demandante de su derecho de acceso a os órganos jurisdiccionales y vulnerar, por tanto, el derecho fundamental a la tutela judicial efectiva ${ }^{\mathrm{I}}$. De hecho, la jurisprudencia emanada del Tribunal Europeo de Derechos Humanos y del Tribunal de Justicia

\footnotetext{
${ }^{\mathrm{r} 2}$ Ello no obstante, debe señalarse que Francia instauró las tasas judiciales en 20 II de manera muy tímida, aunque las volvió a eliminar con carácter general en 2013 salvo una tasa judicial de 225 para la interposición del recurso de apelación en los procesos civiles y sociales en los supuestos en que la asistencia letrada resulte obligada.

${ }^{13}$ Cfr. Council of Europe, European judicial systems: efficiency and quality of Justice, The European Commission for the Efficiency of Justice, Strasbourg 20I6, p. 65.

${ }^{14}$ Vd. European Union Agency for Fundamental Rights, Manual sobre el Derecho Europeo relativo al acceso a la Justicia (trad. LiÉBAnA OrTIZ, J. R.), Oficina de Publicaciones de la Unión Europea, Luxemburgo 20I6, p. I29.

${ }^{15}$ Cfr. European Union Agency for Fundamental Rights, Manual sobre el Derecho Europeo relativo al acceso a la Justicia, cit., p. I29.
} 
de la Unión Europea así lo pone de manifiesto ${ }^{16}$. Siguiendo en este punto a DOMÉNECH PASCUAL se puede concluir que la doctrina general del Tribunal Europeo de Derechos Humanos es que «las restricciones del derecho a la tutela judicial efectiva son admisibles si persiguen un fin legítimo y existe una razonable relación de proporcionalidad entre éste y los medios empleados para alcanzarlo (...) Del art. 6.I CEDH no se deriva un derecho incondicional a la gratuidad del proceso. Las tasas judiciales contribuyen al logro de dos fines plausibles: la financiación del sistema judicial y la reducción del número de litigios injustificados. Ahora bien, la limitación del referido derecho que encierran estos tributos puede resultar desproporcionada si su cuantía resulta excesiva, habida cuenta de circunstancias tales como: la capacidad del justiciable para satisfacerlos; las posibilidades de modular su cuantía y su pago en atención a las singularidades del caso; la fase del procedimiento en la que han de pagarse; la naturaleza del pleito, y la razonabilidad de las pretensiones sostenidas por el sujeto pasivo» ${ }^{17}$.

En definitiva, las cuantías de las tasas judiciales dependen del tipo de proceso y de su complejidad. El corolario de este sistema de financiación de la justicia es la existencia de un sistema de asistencia jurídica gratuita en el que se exime del paso de las tasas judiciales a quienes acreditan falta de capacidad económica. En este sentido, también resulta interesante la conclusión del Consejo de Europa: España hizo un importante esfuerzo económico para aumentar el gasto asociado a la asistencia jurídica gratuita en el 20I2, cuando entraron en vigor las tasas judiciales y, a pesar de la crisis económica, mantuvo ese esfuerzo económico que volvió a aumentar, siquiera mínimamente, en 20I4, último año disponible ${ }^{\mathrm{r} 8}$.

Cabe concluir, por consiguiente, que la exacción de tasas judiciales en España no supondría una excepción respecto del resto de los países europeos; es más, la excepción es precisamente que no se giren tasas judiciales para el acceso a la justicia. A mayor abundamiento, la existencia de un importante sistema de asistencia jurídica gratuita garantiza que la implantación de las tasas judiciales en España no supone una vulneración del art. 6.I del Convenio Europeo de Derechos Humanos o con el art. 47 de la Carta de los Derechos Fundamentales de la Unión Europea.

\footnotetext{
${ }^{16}$ Cfr. las SSTEDH Julin c. Estonia, núm. 16563/08, de 29 de mayo de 2012, 『160; Perdigao c. Portugal, núm. 24768/06, de I6 de noviembre de 20I0, \74; Casanovas c. Francia, núm. I5I4/06, 28 de octubre de 2008, \II.3; Kijewska c. Polonia, núm. 73002/oI, 6 de septiembre de 2007, \47; Stankov c. Bulgaria, núm. 68490/0I, I2 de junio de 2007, \47; Kreuz c. Polonia, núm. 28249/95, de I9 de junio de 200I, 『6I-67. Vid. también las SSTJUE C530/II, Comisión Europea c. Reino Unido de Gran Bretaña e Irlanda del Norte, de I3 de febrero de 20I4, C-260/II, The Queen, a instancia de David Edwards y Lilian Pallikaropoulos c. Environment Agency y otros, de in de abril de 2013 .

${ }^{17}$ Cfr. Doménech Pascual, G., «Las tasas judiciales a juicio», cit., pp. 26-32.

${ }^{\mathrm{I} 8}$ Vid. Council of Europe, European judicial systems: efficiency and quality of Justice, cit., pp. 78. En efecto, según los datos de la Comisión Europea para la Eficacia de la Justicia, el Presupuesto del Reino de España para asistencia jurídica gratuita pasó de los 35.477.067 en 2010 a los 253.034.64I en 20I2, y en 20I4 llegó a los 237.58I.907 .
} 


\section{Las tasas judiciales en los ordenamientos jurídicos español y británico}

\section{III.I. En el ordenamiento jurídico español}

Las denominadas tasas judiciales son un tributo de carácter estatal, cuya gestión tiene encomendada Ministerio de Hacienda y Administraciones Públicas, que deben satisfacer en determinados supuestos los usuarios, ya sean personas físicas o jurídicas, por acudir a los Tribunales y hacer uso del servicio público de la Administración de Justicia.

Aunque la posibilidad de exigir el pago de estas tasas entró en vigor el i de abril de 2003, su exigencia no se reguló de manera efectiva hasta la Ley Io/2012 de 20 de noviembre, posteriormente modificada por Real Decreto-Ley 3/20I3, de 22 de febrero, por la que se regulan determinadas tasas en el ámbito de la Administración de Justicia y del Instituto Nacional de Toxicología y Ciencias Forenses ${ }^{\text {19 }}$.

Como ya se señaló supra en el epígrafe I, La popularmente conocida como la Ley de Tasas Judiciales ha sido muy criticada incluso antes de su aprobación y, para tratar de minimizar el impacto social de las tasas judiciales en el Real Decreto-ley I/2015, de 27 de febrero, de mecanismo de segunda oportunidad, reducción de carga financiera y otras medidas de orden social el Gobierno eximió a las personas físicas de su pago en todo caso desde el i de marzo de 20I5. En julio de 2016 el Tribunal Constitucional anuló el resto de las tasas judiciales. En el presente epígrafe analizaremos la regulación y las causas de la supresión de las tasas judiciales.

\section{III.I.I. Hecho imponible y cuota tributaria}

No está de más recordar, siquiera brevemente, que el artículo I de la Ley Io/20I2 establece que la tasa por el ejercicio de la potestad jurisdiccional en los órdenes civil, contencioso-administrativo y social (que así se denominan técnicamente) tiene carácter estatal y es exigible por igual en todo el territorio nacional en los supuestos previstos en esta Ley, sin perjuicio de las tasas y demás tributos que puedan exigir las Comunidades Autónomas en el ejercicio de sus respectivas competencias financiera.

Pues bien, originariamente constituía el hecho imponible de la tasa el ejercicio de la potestad jurisdiccional originada por el ejercicio de los siguientes actos procesales: a) La interposición de la demanda en toda clase de procesos declarativos y de ejecución de títulos ejecutivos extrajudiciales en el orden jurisdiccional civil, la formulación de reconvención y la petición inicial del proceso monitorio y del proceso monitorio europeo; b) La solicitud de concurso necesario y la demanda incidental en procesos concursales; c) La interposición del recurso contencioso-administrativo; d) La interposición del recurso extraordinario por

\footnotetext{
19 Tal polémica generó esta Ley desde su aprobación que contra ella se interpusieron, salvo error u omisión, nueve cuestiones de inconstitucionalidad, una cuestión prejudicial de Derecho europeo (que, por cierto, fue inadmitida a trámite por el Tribunal de Justicia de la Unión Europea), y cinco recursos de inconstitucionalidad interpuestos por el Gobierno de Canarias y la Diputación General de Aragón, la Generalitat de Cataluña, la Junta de Andalucía y el Grupo Parlamentario Socialista; siendo éste último el que dio lugar a la Sentencia del Tribunal Constitucional I40/20I6, de 2 I de julio de 20I6, que analizaremos infra.
} 
infracción procesal en el ámbito civil; e) La interposición de recursos de apelación contra sentencias y de casación en el orden civil y contencioso-administrativo; f) La interposición de recursos de suplicación y de casación en el orden social; y g) La oposición a la ejecución de títulos judiciales.

$\mathrm{Y}$, aunque en su artículo 3 se establece genéricamente que es sujeto pasivo de la tasa quien promueva el ejercicio de la potestad jurisdiccional, sin embargo, la Ley Iо/20I2 establece una serie de exenciones objetivas y subjetivas. Las exenciones objetivas al pago de las tasas judicial recogen una serie de materias que el legislador entiende necesitadas de especial protección (la interposición de demanda y la presentación de ulteriores recursos en relación con los procesos de capacidad, filiación, matrimonio y menores, o en relación con los procedimientos especialmente establecidos para la protección de los derechos fundamentales y libertades públicas, e. g.) o cuyo gravamen supondría una excesiva onerosidad jurídica (concursos voluntarios, acciones de los administradores concursales en interés de la masa, los procedimientos de división judicial de patrimonial, v. gr.). Las exenciones subjetivas excluyen del pago de tasas judiciales a todas las Administraciones públicas (Administración General del Estado, de las Comunidades Autónomas, las Entidades Locales, así como los organismos públicos dependientes de ellas, y las Cortes Generales y las Asambleas Legislativas de las Comunidades Autónomas), al Ministerio Fiscal y, a partir del 30 de julio de $2015^{20}$, a las personas físicas y a las personas jurídicas a las que se les haya reconocido el derecho a la asistencia jurídica gratuita, acreditando que cumplen los requisitos para ello de acuerdo con su normativa reguladora.

Por lo que respecta a la cuota tributaria, originariamente estaba compuesta por la suma de una cuota fija que se determinaba en función de la clase de procedimiento y orden jurisdiccional, más otra cuota variable consistente en la cantidad que resultaba de aplicar a la base imponible determinada según las normas procesales el tipo de gravamen que resultaba de aplicación en función de las tablas que a continuación se exponen.

Estos gravámenes entraron en vigor en diciembre de $20 \mathrm{I} 2$ con subidas de entre 50 y 750 euros, introduciendo por primera vez el pago en el orden Social y un coste de hasta I.200 euros en recursos ante el Tribunal Supremo en la vía civil y contencioso-administrativa, si bien posteriormente el Gobierno aprobó una reducción del 80 por ciento del tramo variable de las tarifas que se impone según el objeto del litigio.

\section{III.I.2. Tasas judiciales y tutela judicial efectiva}

El Ministro de Justicia justificó la Ley Io/20I2 por la necesidad de frenar la alta litigiosidad existente en nuestro país. Un argumento que desde luego resulta peligroso. De hecho, todos los recursos y cuestiones de inconstitucionalidad se fundamentan que en que las

\footnotetext{
${ }^{20}$ Recuérdese que, tras una queja generalizada de la abogacía española canalizada a través de su Consejo General, el apartado uno del artículo io de la Ley 25/20I5, de 28 de julio, de mecanismo de segunda oportunidad, reducción de la carga financiera y otras medidas de orden social modificó el artículo 4 de la Ley Io/20I2 con el objeto de recoger esta exención del pago de las tasas judiciales a las personas físicas.
} 
tasas judiciales pueden estar condicionando el acceso de los ciudadanos a la Justicia y, por lo tanto, vulnerando el artículo 24.I de nuestra Constitución, por lo que cabe analizar sucintamente esta cuestión.

Ya se ha puesto de manifiesto supra en el epígrafe 2 que las tasas judiciales no suponen necesariamente la vulneración del art. 6.I del Convenio Europeo de Derechos Humanos o con el art. 47 de la Carta de los Derechos Fundamentales de la Unión Europea. Se trata ahora de analizar si dichas tasas judiciales pueden conculcar per se el derecho a la tutela judicial efectiva del art. 24 CE:

Así, consideramos que la introducción de una tasa por el ejercicio de la potestad jurisdiccional no supone per se la infracción de la Constitución, ni la vulneración de ninguno de los derechos fundamentales en ella reconocidos. En este sentido, el Tribunal Constitucional ya ha declarado en su Sentencia 20/20I2, de I2 de febrero, que: «el derecho a la tutela judicial efectiva no es un derecho de libertad, ejercitable sin más y directamente a partir de la Constitución, sino que es un derecho prestacional y de configuración legal, cuyo ejercicio está sujeto a la concurrencia de los presupuestos y requisitos procesales que, en cada caso, haya establecido el legislador» ${ }^{21}$. De esta forma, el legislador cuenta con un amplio ámbito de libertad en la definición o determinación de las condiciones y consecuencias del acceso a la justicia, pues a él incumbe configurar el proceso en cuyo seno se ejercita el derecho fundamental ordenado a la satisfacción de pretensiones dirigidas a la defensa de derechos e intereses legítimos ${ }^{22}$.

Ahora bien, la Ley Io/20I2 podía establecer límites al ejercicio de la tutela judicial efectiva que serán constitucionalmente válidos sólo si, respetando su contenido esencial (art. 53.I CE), están dirigidos a preservar otros derechos, bienes o intereses constitucionalmente protegidos y guardan la adecuada proporcionalidad con la naturaleza del proceso y la finalidad perseguida $^{23}$. De esta forma, el derecho fundamental reconocido en el art. 24.I CE puede verse conculcado por aquellas disposiciones legales que impongan requisitos impeditivos $u$ obstativos del acceso a la tutela jurisdiccional de los derechos e intereses legítimos, si tales trabas resultan innecesarias, excesivas y/o carecen de razonabilidad o proporcionalidad respecto de los fines que lícitamente puede perseguir el legislador ${ }^{24}$.

Por consiguiente, la cuestión es determinar cuál es el coste aceptable que deben soportar los ciudadanos, teniendo en cuenta la necesidad de preservar la tutela judicial efectiva. Los factores que se deben tener en cuenta para determinar este equilibro son la extensión de la exención de las tasas, la vulnerabilidad del demandante y sus medios respecto del demandado, para garantizar el principio de igualdad de armas especialmente en el caso de los ciudadanos o

\footnotetext{
${ }^{21}$ Vid., igualmente, SSTC 99/1985, de 30 de septiembre, FJ 4 ; y I82/2004, de 2 de noviembre, FJ $2^{\circ}$.

${ }^{22}$ Cfr. STC 206/1987, de 2I de diciembre, FJ 5 .

${ }^{23}$ Así, SSTC I58/1987, de 20 de octubre, FJ 4; 32/I99I, de I4 de febrero, FJ 4; y, especialmente, I33/2004, de 22 de julio, $\mathrm{FJ}_{4}^{\circ}$.

${ }^{24}$ En este sentido vid., por ejemplo, SSTC 60/1989, de I6 de marzo, FJ $4^{\text {a } ; ~ I I 4 / I 992, ~ d e ~ I 4 ~ d e ~ s e p t i e m b r e, ~ F J ~} 3^{\text {o; }}$ y 273/2005, de 27 de octubre, FJ $5^{\circ}$.
} 
las pequeñas y medianas empresas que pretende hacer valer sus derechos frente al estado o las multinacionales. El principio general aplicable debe ser que cuando exista conflicto entre el objetivo de recuperar todo el coste del servicio y preservar el derecho a la tutela judicial el efectiva, éste último debe prevalecer. En definitiva, se trata de establecer un justo medio aristotélico en la tensión entre el derecho fundamental a la tutela judicial efectiva y el coste de la prestación de dicho servicio.

En todo caso, resulta adecuado señalar que de acuerdo con el estudio estadístico monográfico sobre los efectos de la modificación de las tasas judiciales, elaborado por el Consejo General del Poder Judicial, los asuntos ingresados en el orden contenciosoadministrativo en los juzgados españoles cayeron en un 22,9 por ciento durante el primer trimestre del año 20I3, coincidiendo con la entrada en vigor de las nuevas tasas judiciales. Ello sugiere que con la Ley de Tasas se ha frenado la litigiosidad existente en nuestro país. A pesar de ello, los datos del Consejo General del Poder Judicial sobre las sentencias dictadas en primera instancia por los Juzgados de lo Contencioso-Administrativo indican que, en términos generales, las tasas judiciales y la introducción de la regla del vencimiento disuadieron de pleitear principalmente a los justiciables «que no tenían razón», cuyas pretensiones hubieran sido probablemente desestimadas; mientras que el número absoluto de los casos en los que los juzgado dieron la razón y protegieron efectivamente los ciudadanos frente a las ilegalidades cometidas por las Administraciones públicas se mantuvo constante e incluso se incrementó ligeramente ${ }^{25}$.

Sin embargo, como ha reconocido el propio Subsecretario de Estado del Ministerio de Justicia en el Congreso de los Diputados, la recaudación por las tasas es muy inferior a la prevista; lo que hace a la ley ineficiente desde este punto de vista. Tampoco se cuenta con una estadística fiable sobre cuánto se ha recaudado por este concepto. La única información fidedigna al respecto, es la proporcionada por el propio Ministro de Justicia en sede Parlamentaria: la recaudación por tasas judiciales de diciembre de 2012 a enero de 2015 ascendió a 639,I3I millones de euros.

III.I.3. La anulación (parcial) de las tasas judiciales

Como ya se ha apuntado, el Real Decreto-ley I/2015, de 27 de febrero, de mecanismo de segunda oportunidad, reducción de carga financiera y otras medidas de orden social eximió a las personas físicas del pago de las tasas judiciales en todo caso desde el I de marzo de 2015 . Pero el Ministro de Justicia mantuvo el pago de las tasas judiciales para las personas jurídicas, ya fueran grandes empresas o pymes, asociaciones y organizaciones no gubernamentales sin ánimo de lucro o partidos políticos.

Sobre esta última cuestión se pronunció por unanimidad el Pleno del Tribunal Constitucional en su Sentencia I40/2016, de 2i de julio de 2016, que ha declarado nulas por inconstitucionales las tasas judiciales impuestas a las personas jurídicas impulsadas en su

\footnotetext{
${ }^{25}$ Vid. Consejo General del Poder Judicial, La justicia dato a Dato. Año 2015, Madrid 20ı6, p. 93.
} 
momento por el exministro de Justicia Alberto Ruiz-Gallardón, y confirmadas por el Ministro de Justicia Rafael Catalá.

En concreto, el Tribunal Constitucional anuló los incisos del art. 7.I de la ley que preveían las siguientes cuotas fijas: I) la de 200 euros para interponer el recurso contenciosoadministrativo abreviado y la de 350 euros para interponer el recurso contenciosoadministrativo ordinario; 2) la de 800 euros para promover recurso de apelación y de 1.200 euros para los recursos de casación y extraordinario por infracción procesal, en el orden civil; 3 ) la de 800 euros para el recurso de apelación y i.200 euros para el recurso de casación en cualquiera de sus modalidades, en el orden contencioso-administrativo; 4) así como también la nulidad de la tasa de 500 euros para el recurso de suplicación y 750 para el de casación en cualquiera de sus modalidades, ambos del orden social. También declaró inconstitucional el art. 7.2, que imponía una cuota variable cuya cuantía será la que resulte de aplicar al valor económico del litigio el tipo de gravamen que corresponda, según la siguiente escala: de $\bigcirc$ a I.000.000 euros, ०,5\%; el resto, un tipo porcentual del ०,25. Máximo variable: Io.০o० euros.

El Tribunal Constitucional considera que el establecimiento de tasas para el ejercicio de acciones judiciales en los órdenes civil, contencioso-administrativo y social no vulnera, en sí mismo, el derecho fundamental de los ciudadanos a la tutela judicial efectiva (art. 24.I CE); no incumple el mandato de sometimiento de la Administración al control judicial (art. Io6 CE) ni tampoco el principio de gratuidad de la Justicia (art. II9. CE). El legislador, explica la sentencia, tiene libertad para regular los requisitos del acceso gratuito a la Justicia, siempre y cuando garantice el ejercicio de este derecho a quienes acrediten insuficiencia de recursos para litigar.

Ahora bien, considera que la cuantía de las tasas (tanto la cuota fija como la variable) resultan desproporcionadas, y pueden producir un efecto disuasorio en los ciudadanos a la hora de acudir a los Tribunales de Justicia en el ejercicio de su derecho fundamental a la tutela judicial efectiva (art. 24.I CE).

Para llegar a esta conclusión, el Tribunal analiza los requisitos que la doctrina exige a las normas que, como la impugnada, limitan un derecho fundamental: la legitimidad de los fines perseguidos y la proporcionalidad de la medida legislativa.

Los fines perseguidos por la Ley Io/20I2 son constitucionalmente legítimos. Así ocurre con el primero de ellos, que es evitar las «situaciones de abuso» que generan aquellos que no buscan la tutela de los tribunales sino ventajas mediante la dilación de los procedimientos; y también con el segundo, que es la financiación mixta de la Justicia. Respecto a este último, su legitimidad se debe a que el hecho imponible gravado por la tasa no es el servicio público de la Justicia (entendido como dotación de medios materiales y personales), sino el «ejercicio de la potestad jurisdiccional». A través de los procesos, en cada uno de los órdenes jurisdiccionales, se materializa «a diario la función que nuestra Constitución encomienda con carácter exclusivo a los órganos de un Poder del Estado (...) como es el Poder Judicial».

Sin embargo, el Tribunal Constitucional sentencia que la legitimidad de esta segunda finalidad no puede suponer la implantación de unas tasas excesivas que imposibiliten el acceso a la Justicia, garantizado en el art. 24.I CE. Por ello, debe analizarse también la 
proporcionalidad de la medida. Según la doctrina constitucional, para que una medida legislativa se considere proporcionada, debe cumplir con los requisitos de idoneidad, necesidad y proporcionalidad en sentido estricto.

En este caso, la medida no es idónea para conseguir la finalidad de acabar con los recursos abusivos. De hecho, al tratarse de un sistema de tasas en el que todas las personas jurídicas pagan lo mismo, su objetivo de prevenir o disuadir de la interposición de recursos abusivos «se diluye para todo aquel que dispone de medios económicos suficientes»; y, sin embargo, «perjudica (...) al justiciable que ejercita correctamente su derecho a recurrir», que se ve obligado a pagar una tasa con la que se pretende erradicar un comportamiento que le es ajeno. La imposibilidad de establecer un control previo sobre los recursos «no puede justificar la imposición indiscriminada de esa tasa, bajo el sustento de un propósito disuasorio frente a una patología a fin de cuentas minoritaria». Además, en opinión del Alto Tribunal nuestro Ordenamiento Jurídico ya prevé un instrumento disuasorio, como es el depósito para recurrir. La sentencia concluye que la imposición de la tasa no es idónea porque no cumple con su objetivo y porque no existen razones objetivas que justifiquen la imposición de una nueva medida disuasoria por una supuesta falta de eficacia de los depósitos.

Por el contrario, la imposición de la tasa sí es una medida idónea para la consecución del segundo fin, el de la financiación mixta de la justicia. Y también es necesaria, pues no hay una alternativa a la tasa para conseguir la finalidad de «fijar una corresponsabilidad económica por parte de todo aquel que genera la actividad procesal cuya realización produce un coste para el Estado».

El último requisito que analiza el Tribunal Constitucional es el de la proporcionalidad en sentido estricto. En el caso de la cuota fija exigida para iniciar un proceso en el orden contencioso administrativo (la demanda no contiene alegaciones sobre el orden civil, lo que impide al Tribunal pronunciarse), la Sentencia advierte que en el acceso a esta jurisdicción no solo está en juego el ejercicio del derecho a la tutela judicial efectiva (art. 24.I CE), sino también la «efectividad» de los mandatos de los arts. I03.I y IO6.I CE con los que se asegura el sometimiento de las Administraciones públicas al control judicial de su actividad.

El efecto disuasorio de dichas tasas no queda anulado ni por el límite establecido (no pueden superar el 50\% la sanción económica recurrida) ni por la reducción del importe de la sanción en caso de pago voluntario. Además, debe tenerse en cuenta que los procesos del orden contencioso-administrativo no se agotan en los recursos contra las multas. El Tribunal Constitucional advierte expresamente de lo gravoso que resulta para el justiciable sumar, al pago de la tasa, los honorarios de abogado y procurador. Por todo ello, la tasa fija de 200 euros para la interposición de un recurso contencioso-administrativo abreviado y la de 350 euros para el ordinario resultan desproporcionadas y por ello contrarias al derecho de acceso a la jurisdicción.

En cuanto a las tasas exigidas para la interposición de los recursos, el Tribunal Constitucional considera que la justificación contenida en la memoria económica de la Ley IO/20I2 es insuficiente, pues se limita a señalar que es legítimo fijarlas en cuantías superiores 
a las de la primera instancia y que su recaudación no es suficiente para cubrir los costes generados por la segunda instancia. A este respecto, la Sentencia afirma, por un lado, que «el objetivo de la financiación mixta de la Justicia no puede traer consigo el sacrificio de un derecho fundamental»; y, por otro, que la cuantía de las tasas para recurrir resoluciones judiciales «no atiende a la realidad económica de una mayoría significativa de sus destinatarios, a los cuales resulta excesiva». En consecuencia, esas tasan vulneran el derecho protegido por el art. 24.I CE al poder disuadir de la voluntad de interponer el recurso.

Respecto a la cuota variable (segunda cantidad que se exige al justiciable en función de un determinado porcentaje sobre el valor económico del litigio), el Pleno del Constitucional considera que «eleva innecesariamente la carga económica» sobre el recurrente sin que el legislador especifique a qué criterio responde su exigencia. Por tanto, resulta inconstitucional por infringir el derecho fundamental de acceso a la jurisdicción y al recurso.

En todo caso, la doctrina sentada por la STC I40/20I6 es disconforme con la práctica de la mayoría de países de Europa y con la jurisprudencia al respecto del Tribunal Europeo de Derechos Humanos y del Tribunal de Justicia de la Unión Europea que sí han considerado las tasas judiciales compatibles con el derecho a la tutela judicial efectiva, tal y como hemos puesto de manifiesto en el epígrafe 2. Igualmente crítico con esta sentencia del Alto Tribunal se muestra Doménech Pascual, para quien «la solución sentada y los argumentos empleados para tratar de sostenerla [STC I40/20I6] van a dificultar enormemente que en las próximas décadas algún Gobierno se atreva a intentar introducir un régimen de tasas judiciales siquiera cercanas a las vigentes en la mayor parte de Europa. Se hurta así al Parlamento la posibilidad de servirse de un instrumento de racionalización de la Administración de Justicia utilizado con toda normalidad en numerosos países de nuestro entorno, cuya proporcionalidad no ha sido cuestionada con carácter general y que no parece que haya dado allí malos resultados» ${ }^{26}$.

En todo caso, siguiendo el interesante análisis al respecto de DEL CARPIO FIESTAS ${ }^{27}$, el efecto práctico de la STC I40/20I6, de 2I de julio, sobre la Ley Io/20I2 es el siguiente: a) se suprime la parte variable de todas las tasas judiciales; b) se suprimen las tasas en los órdenes jurisdiccionales contencioso-administrativo y laboral; c) se mantienen parcialmente tasas judiciales en el orden jurisdiccional civil, excluyéndose ex lege a las personas físicas, por los siguientes conceptos y cuantías: I) juicio verbal y cambiario: 150 ;2) juicio ordinario: $300 €$; 3 ) juicios monitorio y monitorio europeo, así como demanda incidental en el proceso concursal: Io० €; 4) ejecución extrajudicial y oposición a la ejecución de títulos judiciales: 200 €; y 5) concurso necesario: $200 €$.

Debemos señalar también que el Tribunal Constitucional aclara que, en virtud del principio de seguridad jurídica, la declaración de nulidad de las tasas sólo producirá efectos «pro futuro», esto es, en relación con nuevos supuestos o con los procedimientos donde no

\footnotetext{
${ }^{26}$ Cfr. DoméneCh PASCUAL, G., «Las tasas judiciales a juicio», cit., p. 52.

${ }^{27}$ Vid. Del Carpio Fiestas, V., «Tasas judiciales, técnica legislativa y Estado de Derecho», en DíEZ-PICAzo GiméneZ, I. y Vegas Torres, J. (Coords.), Derecho, Justicia, Universidad. Liber amicorum de Andrés de la Oliva Santos, Centro de Estudios Ramón Areces, Madrid 20I6, pp. IoI9-I042.
} 
haya recaído una resolución firme. Así, de una apriorística interpretación literal de la Sentencia, no cabe la devolución de las cantidades pagadas en relación con las tasas declaradas nulas ni en los procedimientos finalizados por resolución firme ni tampoco en los no finalizados en el que el pago de la tasa se satisfizo sin que fuera impugnada por vulneración del art. 24.I CE.

Ahora bien, cabe argüir que existen vías jurídicas para reclamar las tasas judiciales declaradas nulas por el Tribunal Constitucional. En primer lugar, debe señalarse que la STC I40/20I6 se limita a declarar la inconstitucionalidad de las tasas judiciales en la versión vigente a 2 I de julio de 2016 de la Ley ıо/20I2, es decir la aplicable exclusivamente a pequeñas y medianas empresas, organizaciones no gubernamentales y gran empresa, y por tanto sólo respecto de ellas se aplica la limitación que se introduce en su Fundamento Jurídico re. En consecuencia, resulta constitucionalmente lícito solicitar la devolución de las tasas judiciales cobradas a las personas físicas, porque a ellas no les afecta la limitación establecida en la Sentencia analizada.

Por otra parte, también se puede argumentar que existe una vía jurídico-tributaria para reclamar las tasas judiciales cobradas a personas jurídicas. Así, la conexión entre los artículos 22I.4 y I20.3 de la Ley General Tributaria, en el ámbito de las situaciones activas del contribuyente, establece el derecho subjetivo por antonomasia del particular frente a la Administración tributaria: la devolución de ingresos indebidos. El obligado tributario tiene derecho a solicitar la rectificación de una autoliquidación cuando considere que ésta ha perjudicado de cualquier modo sus intereses legítimos, dando lugar, en su caso, a la devolución de los correspondientes ingresos indebidos. Por tanto, la autoliquidación de una tasa judicial puede rectificarse en los cuatro años siguientes a su presentación (art. 66.c de la Ley General Tributaria), de tal suerte que hasta entonces no puede hablarse en modo alguno de que el obligado al pago «la satisfizo sin impugnarla», y mucho menos aún de firmeza del tributo, como hace el Tribunal Constitucional, en tanto en cuanto su pago, vía autoliquidación, sigue siendo revisable hasta el transcurso de dicho plazo. Es más, uno tiene la impresión de que se mezclan conceptos, pues una cosa es la firmeza del procedimiento judicial que se haya ventilado y por el que se haya satisfecho la tasa, y otra muy distinta es la de la propia tasa judicial, cuya rectificación puede instarse en cualquier momento dentro del plazo referido. Otra interpretación supondría negarle al contribuyente el ejercicio de un derecho consagrado legalmente a recuperar lo que es suyo, por haberse satisfecho sobre una base normativa declarada inconstitucional.

Con todo, el Compromiso 138 para mejorar España que firmaron el 28 de agosto de 2016 los Portavoces en el Congreso de los Diputados del Grupo Popular y del Grupo Ciudadanos prevé reformar la Ley de tasas judiciales para adaptar su contenido a la Sentencia del Tribunal Constitucional I40/20I6, sin que en ningún caso suponga un incremento de estas, especialmente a las pequeñas y medianas empresas y a las entidades sin ánimo de lucro. Nos consta que en el momento de escribir estas líneas el Ministerio de Justicia se halla trabajando en el borrador de una nueva Ley de Tasas Judiciales. 
III.2. En el ordenamiento jurídico inglés

III.2.I. Las tasas judiciales en general

La cuestión de las tasas judiciales en el sistema procesal británico tampoco es nueva ${ }^{28}$. Ello no obstante, en el Reino Unido también debe pagarse tasas tanto para presentar una demanda como para interponer un recurso contra una resolución judicial, cuya cuantía también depende del asunto de que se trate. De hecho, en el Reino Unido e Irlanda del Norte los ingresos procedentes de las tasas judiciales representan más de la mitad del presupuesto destinado anualmente a la Administración de Justicia. Centrándonos en las tasas judiciales de Inglaterra y $\mathrm{Gales}^{29}$, en el orden jurisdiccional civil éstas van desde las 25 libras esterlinas para un juicio monitorio, pasando por las 550 libras esterlinas para la interposición de una demanda de divorcio, hasta las 655 libras esterlinas para un proceso concursal $1^{30}$.

En el Reino Unido el problema que surge es idéntico que en el caso español, a saber: unas tasas judiciales elevadas desincentiva el acceso a la justicia. Al igual que ocurre en España, se trata de establecer un justo medio aristotélico en la tensión entre el derecho fundamental a la tutela judicial efectiva y el coste de la prestación de dicho servicio. Aunque nada impide en el sistema jurídico británico la existencia de tasas judiciales que soporten directamente aquéllos que acudan a los Tribunales para la defensa de sus derechos o intereses legítimos, la cuestión es determinar cuál es el coste aceptable que deben soportar los ciudadanos, teniendo en cuenta la necesidad de preservar la tutela judicial efectiva. Los factores que se deben tener en cuenta para determinar este equilibro son la extensión de la exención de las tasas, la vulnerabilidad del demandante y sus medios respecto del demandado, para garantizar el principio de igualdad de armas especialmente en el caso de los ciudadanos o las pequeñas y medianas empresas que pretende hacer valer sus derechos frente al estado o las multinacionales. En todo caso, el principio general aplicable es que cuando exista conflicto entre el objetivo de recuperar todo el coste del servicio y preservar el derecho a la tutela judicial el efectiva, éste último debe prevalecer.

\footnotetext{
${ }^{28}$ Baste recordar que Jeremy BENTHAm consideró a fondo todas las cuestiones que, en cualquier tiempo y lugar, suscitan unas tasas judiciales que pueden ser disuasorias $u$ obstativas del acceso a la Justicia en un librito que se publicó en I793. Vid. Bentham, J., Una Protesta contra las Tasas Judiciales, en la que se demuestra la peculiar malignidad de todos estos impuestos como coste añadido al de acudir a la Justicia, Thomson Reuters-Civitas, Cizur Menor 20I3; con introducción y edición anotada a cargo del Profesor De LA Oliva SANTOS. El argumento fundamental del filósofo y jurista inglés es que las tasas judiciales quizá frenen litigios, pero que lo hacen tanto respecto de los que son infundados, como de los que tienen todo el fundamento y lógica que se interpongan, puesto que no se distingue en absoluto entre unos y otros.

${ }^{29}$ Recuérdese que en Reino Unido también se incluyen Escocia e Irlanda del Norte, si bien las tasas judiciales de dichas regiones son diferentes. Las tasas judiciales escocesas pueden consultarse en http://www.scotcourts.gov.uk/taking-action/court-fees y las tasas judiciales de Irlanda del Norte pueden consultarse en http://www.courtsni.gov.uk/en-GB/Services/CourtFees/Pages/CourtFees.aspx ambas webs con último acceso el 3I de octubre de 2017 .

${ }^{30}$ Puede consultarse una completa guía de las tasas judiciales inglesas y galesas para el acceso al orden jurisdiccional civil en el siguiente enlace web https://www.gov.uk/government/publications/fees-for-civil-andfamily-courts con último acceso el 3I de octubre de 2017 .
} 


\section{III.2.2. Las tasas judiciales en el orden social}

Para ilustrar esta cuestión, vamos a centrarnos en la jurisdicción social, porque la exigencia de tasas judiciales para acceder a este orden jurisdiccional se introdujo en julio de 2013 (y son, por tanto, contemporáneas a nuestras tasas judiciales), y porque su cuantía y modo de cálculo son también un tanto complejos.

En efecto, la interposición de una demanda laboral lleva aparejado el pago de una tasa judicial, coste que se introdujo en julio de 2013 con un doble objetivo: rebajar la presión fiscal que supone el mantenimiento del orden jurisdiccional social, que ascendía a 83 millones de libras esterlinas; y estimular entre los ciudadanos el uso de la conciliación, mediación y arbitraje también para resolver conflictos laborales.

En cuanto a la cuantía de tasa judicial, ésta se determina por el tipo de demanda interpuesta: Clase A (reclamaciones por impago de salarios o de indemnización por despido, e. g.) y Clase B (demandas por despido improcedente o por discriminación laboral, e. g.). Además, una parte de la tasa se paga cuando se interpone la demanda (la denominada 'tasa de expedición') y el resto cuando se ordena la apertura del juicio oral (la denominada 'tasa de audiencia'). En total, una demanda laboral de Clase A cuesta 390 libras esterlinas ( $£$ I60 la 'tasa de expedición’ y £230 la 'tasa de audiencia') y una demanda laboral de Clase B cuesta I.200 libras esterlinas ( $£ 250$ la 'tasa de expedición' y £950 la 'tasa de audiencia’).

También en el sistema inglés se prevé la posibilidad de exención de pago de tasas judiciales siempre que el demandante cumpla una serie de requisitos, si bien resulta bastante complicado ya que supone superar un test doble. Para obtener la exención total de pago de la tasa, el demandante debe superar un test de renta disponible y posteriormente un test de ingresos brutos mensuales con respecto a cada una de los pagos ('tasa de expedición' y 'tasa de audiencia') en que se subdivide la tasa judicial en el orden social. También cabe que quien supere alguno de los umbrales puede otorgársele una exención parcial de la tasa judicial.

En todo caso, la introducción de las tasas judiciales en el orden social supuso una impresionante caía en el número de demandas laborales de la noche a la mañana: las demandas individuales cayeron un $67 \%$ y las demandas colectivas un $72 \%$.

\footnotetext{
${ }^{31}$ Ello no obstante, una de las mayores críticas al sistema de exención de pago de las tasas judiciales es precisamente el relativo a los umbrales de ambos tests, que se aplican por separado para la 'tasa de expedición' y para la 'tasa de audiencia'. Por ejemplo, respecto del test de renta disponible, para una tasa de hasta I.000 libras esterlinas el umbral es de 3.000 libras esterlinas, mientras que para una tasa de entre I.०0 у I.335 libras esterlinas el umbral es de 4.000 libras esterlinas. Ello implica que para una demanda de Clase B, con una 'tasa de expedición' de 250 libras esterlinas y una 'tasa de audiencia' de 950 libras esterlinas, se aplica un umbral de capital disponible de 3.000 libras esterlinas para cada tasa. Sin embargo, si ambas tasas se tomaran en conjunto (es decir, I.200 libras esterlinas) se aplicaría un umbral de 4.000 libras esterlinas, lo que sería mucho más beneficioso para los solicitantes de exención en el pago de la tasa.

${ }^{32}$ Las estadísticas sobre incoación de procesos laborales en el primer trimestre de 2013 y en el primer trimestre de 2015 muestra una reducción muy significativa del número de demandas laborales típicas: reclamaciones de horas extras (78\%); reclamación de cantidades $(56 \%)$, despido disciplinario (72\%), reclamaciones salariales $(58 \%)$, incumplimiento contractual (75\%), discriminación sexual (68\%) y medidas contra o despido por embarazo (40\%).
} 
Esta reducción de la litigiosidad puede deberse en parte a la creación de un common law de la mediación inglesa ${ }^{33}$, y al hecho de que la conciliación previa al juicio sea obligatoria. No obstante, el Servicio de Conciliación y Arbitraje británico ha puesto de manifiesto que el 26\% de los posibles demandantes laborales desisten de acudir a los Tribunales por la obligación de pagar las tasas judiciales.

III.2.3. Tasas judiciales en el orden social y tutela judicial efectiva

El Tribunal Supremo del Reino Unido ha tenido la oportunidad de pronunciarse sobre la cuestión de las tasas judiciales en el orden laboral en su Sentencia R (on the application of UNISON) v. Lord Chancellor [20I7] UKSC $5 \mathrm{I}^{34}$.

Se trata de una sentencia en la que se discutía si el Ministro de Justicia se excedió en su competencia al promulgar una Orden que el demandante (el sindicato de trabajadores UNISON) consideraba que imponía unas muy elevadas tasas judiciales a quienes pretendieran demandar ante los juzgados y tribunales de los social (vid. \I6-20) con el objeto de desplazar los costes de la Administración de Justicia de los contribuyentes a sus concretos usuarios (vid. § II).

Como se puede observar, al igual que en el caso español, también en Reino Unido se viene a luchar contra la supuesta privatización de la justicia y, como se podrá comprobar a continuación, los argumentos del Tribunal Supremo británico son similares a los del español.

En efecto, la sentencia reconoce que el derecho constitucional de acceso a los tribunales es inherente al Estado de Derecho del common law (vid. \66), de tal forma que cualquier obstáculo o impedimento por parte del ejecutivo del derecho de acceso a los tribunales requiere una autorización clara del Parlamento (vid. 『77).

A decir del Tribunal Supremo, en el sistema procesal inglés resulta razonable que las demandas laborales se resuelvan mediante negociación o mediación, de tal forma que la Ley de tasas británica tiene un cierto efecto disuasorio en el bien entendido de que el mecanismo

\footnotetext{
${ }^{33}$ En efecto, la introducción de la mediación en el sistema procesal civil británico ha sido tan bien aceptada por la judicatura que se ha desarrollado un common law de la mediación inglesa mediante el que, a través de diversos pronunciamientos jurisdiccionales [Cfr., por ejemplo, Cowl and Other v. Plymouth City Council (200I) EWCA Civ I935; Hurst v. Leeming (200I) EWHC 105I Ch; Dunnet v. Railtrack Plc. (2002) EWCA Civ 2003], los abogados de las partes en litigio saben que por imperativo legal deben recurrir a la mediación antes que incoar proceso jurisdicción, incluso cuando la discusión sea sobre una cuestión de interpretación jurídica [Vid., por ejemplo, Royal Bank of Canada Trust Corporation Ltd. v Secretary of State for Defense (2003) EWHC I479 Ch. Esta Sentencia, además, deja claro que es peligroso para la Administración pública el ignorar su propia vinculación al uso de los sistema de resolución alternativa de conflictos], y que la negativa injustificada a someterse a mediación, o abandonar el procedimiento injustificadamente, supondrá una condena en costas adicional ya que «el abandono del procedimiento de mediación es contrario al espíritu de la Ley de Enjuiciamiento Civil» [así, Leicester Circuits Ltd. v. Coates Brothers Plc. (2003) EWCA Civ 290], incluso la falta de respuesta a una invitación a un procedimiento de mediación podría ser considerado como inadmisible por el Tribunal [vid., PGF II SA v. OMFS Company and another (20I2) EWHC 83 TCC].

${ }^{34}$ Puede leerse el texto íntegro de la sentencia en https://www.supremecourt.uk/cases/docs/uksc-2015-0233judgment.pdf (último acceso 3I de octubre de 20I7).
} 
diseñado por el legislador sirve para apuntalar los métodos alternativos de resolución de conflictos que las partes tienen a su disposición (así, \72, vid también $\int \mathbb{\int}$ I03 y I04).

Ello no obstante, el Tribunal Supremo sostiene igualmente que si la orden ministerial crea un riesgo real de que las personas efectivamente no puedan acceder a la justicia, resultaría un acto ultra vires (vid \87). De hecho, incluso cuando la Ley de tasas judiciales británica autoriza la imposición de una intromisión en el derecho de acceso a la justicia, se presume que está sujeta a una limitación implícita y que el grado de intrusión no debe ser mayor de lo que se justifica por los objetivos que la medida debe servir (así, \88).

En concreto, esta sentencia del Tribunal Supremo concluye que para que las tasas judiciales se ajusten a Derecho deben establecerse unas cuantías que todos los ciudadanos puedan pagar, teniendo en cuenta la posibilidad de exoneración total o parcial de las mismas por poderse acoger el demandante al derecho de asistencia jurídica gratuita (vid \9I)

En cuanto a los concretos hechos enjuiciados en esta sentencia, el Tribunal Supremo consideró que la Orden de tasas judiciales en el orden social, dictada por el Ministerio de Justicia, impide efectivamente el acceso a la justicia y, por lo tanto, es ilegal en virtud tanto de la legislación británica como del Derecho de la Unión Europea (vid \98). A mayor abundamiento, como impedía el acceso a la justicia desde el mismo momento en que entró en vigor, la sentencia declara que la Orden de tasas judiciales es ilegal ab initio, y debe ser anulada (así

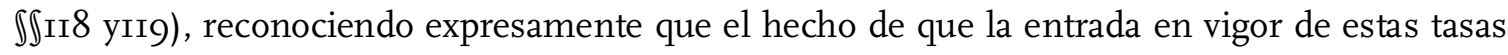
judiciales en el orden social por orden ejecutiva hizo que a los trabajadores sin recursos económicos suficientes para pagarlas se les negase la tutela judicial efectiva sin la habilitación legal necesaria bien podría conducir a una cascada de demandas.

Resulta interesante resaltar, además, que el Magistrado Ponente Lord Reed determinó si existía un riesgo real de que las personas efectivamente no pudieran acceder a la justicia, no por referencia a las circunstancias económicas concretas de los demandantes individuales, sino por referencia a la evidencia estadística contenida en los informes oficiales.

Así, el Magistrado Ponente sostiene que la evidencia, considerada de manera realista y en conjunto, debe llevar a la conclusión de que este requisito no se cumple con las tasas judiciales en el orden social. Como concluye el Review Report, «está claro que ha habido una caída aguda, sustancial y sostenida en el volumen de demandas laborales como resultado de la introducción de las tasas judiciales en este orden jurisdiccional». Si bien el Review Report afirma que no hay evidencia concluyente de que la exacción de tasas judiciales en este orden jurisdiccional haya impedido que los trabajadores presenten demandas laborales, el Tribunal Supremo no requiere evidencia concluyente: basta con que se demuestre un riesgo rea ${ }^{35}$. En cualquier caso, la disminución del número de demandas laborales ha sido tan aguda, tan sustancial y tan sostenida que justifica la conclusión de la sentencia de que un número importante de personas que de otro modo habrían presentado demanda laboral han considerado que las tasas judiciales no son asequibles (vid $\mathbb{9 I}$ ).

\footnotetext{
${ }^{35}$ En este sentido, vid. Divisional Court in R (Hillingdon London Borough Council) v Lord Chancellor (Law Society intervening) [2008] EWHC 2683 (Admin); [2009] I FLR 39, \6I.
} 


\section{III.2.4. La reforma de las tasas judiciales}

La Comisión de Justicia del Parlamento británico encargó un Informe sobre las Tasas Judiciales que fue publicado en junio de $2016^{36}$, y cuya principal conclusión es que resulta preciso llevar a cabo importantes modificaciones de las tasas judiciales para restaurar un nivel aceptable de acceso a la justicia para los ciudadanos.

Respecto de las tasas judiciales en el orden social, dicho Informe solicita al Parlamento británico que se tomen las medidas legales oportunas para: reducir de manera sustancial la cuantía total de las tasas; reconsiderar la clasificación binaria (A y B) de las demandas laborales en función de su complejidad; aumentar los umbrales de renta disponible e ingresos brutos mensuales para la aplicación de la exención total de las tasas judiciales; y revisar en su conjunto la posición jurídica de las mujeres que presentan demandas laborales por discriminación a causa de su maternidad o embarazo, y en especial para estos casos el plazo de tres meses para la presentación de la demanda debería modificarse.

Respecto de las tasas judiciales en el resto de órdenes jurisdiccionales, las recomendaciones del mencionado Informe son las siguientes: el Gobierno debería revisar el impacto del incremento de las tasas judiciales aprobado en abril de 2015 relativo a las demandas por reclamación de cantidades para que Londres sigua siendo competitiva como centro de litigación internacional; el incremento de la tasa judicial para las demandas de divorcio, de 4 IO a 550 libras esterlinas, debería ser anulada; debería establecer un sistema gradual para el pago de las tasas judiciales en las demandas de Derecho de familia; el Ministerio de Justicia debería introducir un sistema de recalificación periódica de los umbrales de exención del pago de las tasas judiciales que tenga en cuenta la inflación, y ello debería llevar a una revisión de la asequibilidad de las tasas judiciales en el orden civil y del sistema de exención del bajo, debiendo estudiar también medidas de simplificación del sistema.

Por último, debe señalarse que, aunque en el Reino Unido no se exigía el pago de tasas el acceso a los Juzgados y Tribunales del orden jurisdiccional penal con carácter general, sí que existía la llamada «tasa de los Tribunales penales», y que grababa a los mayores de edad cuando se declaraban culpables o eran condenados en juicio, o cuando recurrían infructuosamente ${ }^{37}$; tasa que se cobraba con la finalidad de recuperar parte de los costes de funcionamiento del Tribunal, y con independencia de lo que se determinara en la sentencia como condena, adicional en su caso, a la privación de libertad: indemnizaciones a la víctima, responsabilidad civil, multa, honorarios de abogados. Ahora bien, desde el 24 de diciembre de 2015 esta tasa de los Tribunales penales ha sido derogada ya que, aunque la finalidad de que los delincuentes contribuyeran de manera activa en los costes que implica hacer justicia en el caso concreto en

\footnotetext{
${ }^{36} \mathrm{Cfr}$. http://www.publications.parliament.uk/pa/cm20I6I7/cmselect/cmjust/167/167.pdf (último acceso el 3I de octubre de 20I7).

${ }^{37}$ Respecto de la llamada tasa de los Tribunales penales puede consultarse el siguiente enlace web https://www.gov.uk/government/uploads/system/uploads/attachment_data/file/336085/fact-sheet-criminal-courtscharge.pdf con último acceso el 3I de octubre de 2017 .
} 
teoría es loable, en la práctica generaba múltiples problemas, llegando a contravenir incluso el principio constitucional de no declarar contra uno mismo ${ }^{38}$.

Por este motivo, el Ministro de Justicia británico ha ordenado que se revise tanto la estructura como la propia finalidad de las tasas impuestas a los que se declaran culpables o son condenados en un proceso penal para alcanzar un cuádruple objetivo: dotar de mayor simplicidad y claridad al sistema; dar al Poder Judicial una mayor discreción en la fijación de las tasas penales; mejorar las penas pecuniarias en los casos de condenas que no lleven aparejada la pena privativa de libertad; y garantizar que lo recaudado mediante la tasa de los Tribunales penales se destine efectivamente a reducir el coste para el contribuyente del funcionamiento del sistema procesal penal británico.

Como se aprecia, en el Reino Unido el debate no gira en torno a la supresión de las tasas judiciales, sino de su modulación para hacer más asequible el acceso a la justicia de los ciudadanos y empresas.

\section{En favor de las tasas judiciales en el orden jurisdiccional social}

IV.I. Identificación de la problemática

La Ley Io/20ı2 establecía como hecho imponible de las tasas judiciales el ejercicio de la potestad jurisdiccional originada por el ejercicio de, entre otros actos procesales, la interposición de recursos de suplicación y de casación en el orden social (art. 2.f); pero no de la interposición de la demanda en toda clase de procesos declarativos y de ejecución de títulos ejecutivos extrajudiciales en el orden jurisdiccional social.

La razón de que nuestro legislador excluyera la interposición de la demanda laboral de entre los hechos imponibles que daban lugar al pago de la tasa judicial obedece, en nuestra opinión, a la concepción del Derecho laboral como derecho tuitivo según la cual para proteger a la parte más débil de la relación laboral (i. e., el trabajador) impera el derecho de igualdad y no discriminación. De este modo, se habría pretendido evitar los supuestos en que los trabajadores se hubieran visto privados de la posibilidad de defender sus derechos laborales frente a la empresa cuando los consideraran vulnerados al carecer aquéllos de los recursos financieros suficientes para plantear un pleito laboral.

Pero esta razón para la exclusión del pago de tasas judiciales para la interposición de demandas laborales parte de un planteamiento miope de la realidad judicial. En primer lugar, porque en general los trabajadores cuentan con recursos financieros suficientes para hacer frente al pago de unas tasas judiciales de pongamos 350 euros, por analogía con la demanda contencioso-administrativa; especialmente en los conflictos colectivos de trabajo. Además, en los supuestos en que los trabajadores acreditasen que no disponen de recursos financieros

\footnotetext{
${ }^{38} \mathrm{La}$ tasa de los Tribunales penales se cobraba a todo procesado que se declara culpable o al condenado mediante sentencia. La cuantía oscilaba entre las I5o libras esterlinas para aquellos que admitían su culpabilidad en el Juzgado de lo Penal, y las i.20o libras esterlinas para los declarados culpables en el Tribunal Supremo, creando así un desincentivo financiero para que el acusado defendiera su inocencia en todo caso.
} 
suficientes para pagar la tasa judicial que le permitiera interponer la demanda laboral, al igual que ocurría en el resto de órdenes jurisdiccionales, resultaría de aplicación la Ley de asistencia jurídica gratuita en el marco del derecho constitucional previsto en el art. II9 CE. Y, en segundo lugar, porque en la mayoría de las ocasiones los trabajadores que acuden a la jurisdicción social lo hacen asesorados por abogados de sindicato, por lo que no incurren en gastos de asistencia letrada.

Así las cosas, y puesto que en el momento de escribir estas líneas el Ministerio de Justicia se halla trabajando en el borrador de una nueva Ley de tasas judiciales, consideramos oportuno plantear una serie de argumentos para sostener la necesidad de extender las tasas judiciales al orden jurisdiccional social, a pesar de su evidente tuitivo, como de hecho ocurre generalizadamente en los sistemas procesales europeos.

En efecto, se trata de una decisión de estricta política legislativa, pero todos los profesionales de la justicia (judicatura, abogacía y procura, y doctrina) hemos de ser coherentes. Lo que no se puede hacer es demandar más medios económicos para la Justicia del siglo XXI que todos deseamos a la vez que se rechaza de plano la imposición de cualquier tributo a los usuarios de la tuitiva jurisdicción laboral; porque esa reduccionista propuesta en el fondo esconde simples criterios corporativos.

Como se ha señalado en epígrafes precedentes, son dos las motivaciones clásicas que históricamente han constituido el fundamento de política legislativa para el establecimiento de tasas judiciales tanto en España como en Reino Unido 39 : por un lado, la financiación de la prestación del servicio público de administración de justicia; y, por el otro, la reducción de la litigiosidad; argumentos éstos que ya puso de manifiesto en el siglo XVIII Jeremy BENTHAM en su protesta contra las Tasas Judiciales, en la que se demuestra la peculiar malignidad de todos estos impuestos como coste añadido al de acudir a la Justicia, a la que ya nos hemos referido anteriormente.

Aunque no vamos a detenernos a analizar en profundidad la financiación de la prestación del servicio público de administración de justicia ${ }^{40}$, sí debemos apuntar que la cuestión que debe decidir el legislador a la hora de regular ex novo las tasas judiciales es si los

\footnotetext{
${ }^{39}$ Así, en el Apartado I de la Exposición de Motivos de la Ley Io/20I2, de 20 de noviembre, por la que se regulan determinadas tasas en el ámbito de la Administración de Justicia y del Instituto Nacional de Toxicología y Ciencias Forenses se puede leer: «La reciente Sentencia del Tribunal Constitucional 20/20I2, de I6 de febrero de 2012 no sólo ha venido a confirmar la constitucionalidad de las tasas, sino que además expresamente reconoce la viabilidad de un modelo en el que parte del coste de la Administración de Justicia sea soportado por quienes más se benefician de ella. Con esta asunción por los ciudadanos que recurren a los tribunales de parte del coste que ello implica se pretende racionalizar el ejercicio de la potestad jurisdiccional, al mismo tiempo que la tasa aportará unos mayores recursos que permitirán una mejora en la financiación del sistema judicial y, en particular, de la asistencia jurídica gratuita, dentro del régimen general establecido en el artículo 27 de la Ley 47/2003, de 26 de noviembre, General Presupuestaria». Por su parte, el Estudio sobre el potencial impacto en el número de demandas laborales de los cambios propuestos en las tasas judiciales realizado en 2012 por el Servicio Estadístico del Ministerio de Justicia del Reino Unido incide también expresamente en estas dos cuestiones.

${ }^{40}$ Sobre la financiación de los gastos del proceso en relación con las tasas judiciales se ha extendido GonZÁLEZ PÉrez, J., «Las tasas judiciales y la asistencia jurídica gratuita», Anales de la Real Academia de Ciencias Morales Y Políticas, 9 de junio de 20I5, pp. I-I8.
} 
costes de un proceso los debemos soportar todos a través del sistema fiscal, aunque no tengamos intervención en el proceso, o si en todo o en parte deben contribuir los que son parte o aquellos en los que concurran ciertas circunstancias, como haber litigado con temeridad o mala fe.

Sin embargo, sí vamos a analizar con más detenimiento es cómo la implantación de las tasas judiciales para la interposición de la demanda en toda clase de procesos declarativos y de ejecución de títulos ejecutivos extrajudiciales en el orden jurisdiccional social puede ser beneficioso para reducir la litigiosidad laboral, y los beneficios que ello comporta. No se trata de una cuestión menor. Debe tenerse en cuenta que, de acuerdo con los datos de la Comisión Europea para la Eficacia de la Justicia del Consejo de Europa ${ }^{4 \mathrm{I}}$, en $20 \mathrm{I} 4$ la tasa de litigiosidad en España para las demandas de despido en primera instancia fue superior a la media del resto de países de Europa, tal y como se muestra en el siguiente gráfico:

Debemos señalar que la extensión de las tasas judiciales a la interposición de la demanda laboral puede resultar muy ventajosa para el sistema procesal laboral español en su conjunto, precisamente porque con ellas se combatirán las altas tasas de litigiosidad de mala fe que soporta la jurisdicción del orden social.

Como se ha puesto de manifiesto en el caso del Reino Unido ${ }^{42}$, la imposición de tasas judiciales en el orden jurisdiccional social favorece la resolución extrajudicial de conflictos laborales. Por consiguiente, imponer las tasas judiciales en lo laboral supondría dotar de toda su eficacia jurídica al Capítulo primero del Título V del Libro I de la Ley 36/20II, de io de octubre, reguladora de la jurisdicción social, dedicado precisamente a la evitación del proceso social a través de la conciliación, la mediación y el arbitraje laboral ${ }^{43}$. En este sentido, conviene recordar cómo ALCALÁ-ZAMORA Y CASTILLO reconoce que no tiene sentido acudir en todo caso al proceso jurisdiccional, por su elevado coste por simple que sea su tramitación, siendo la autocomposición una fórmula satisfactoria, especialmente por su economía de costo ${ }^{44}$.

A mayor abundamiento, como muy gráficamente ha puesto de manifiesto GoNZÁLEZ PÉREZ, la imposición de tasas judiciales en el orden social puede ayudar a perder en los despachos de abogados los asuntos que se deben perder ${ }^{45}$, en el sentido de que los abogados ya no podrán convencer a sus clientes tan fácilmente de pleitear cuando tengan fundadas razones para esperar una sentencia desfavorable. Por este motivo, las tasas judiciales en lo laboral

\footnotetext{
${ }^{41}$ Vid. Council of Europe, European judicial systems: efficiency and quality of Justice, cit., pp. 202-204.

${ }^{42}$ Sentencia del Tribunal Supremo del Reino Unido R (on the application of UNISON) v. Lord Chancellor [20I7] UKSC 5I, \ 72: «es deseable que las reclamaciones derivadas de presuntas vulneraciones de los derechos laborales se resuelvan mediante conciliación o mediación».

${ }^{43}$ Para un análisis pormenorizado de estos sistemas alternativos de resolución de disputas vid., por todos, Liébana OrTiz, J. R., Solución extrajudicial de conflictos laborales. Conciliación administrativa y mediación y arbitraje autónomos, Thomson Reuters-Aranzadi, Cizur Menor 2017.

${ }^{44}$ Cfr. AlCalÁ-Zamora y Castillo, N., Proceso, autocomposición $y$ autodefensa, $3^{\text {a }}$ ed, UNAM, México 2000 , pp. I3I4.

${ }^{45}$ Cfr. GonZÁlez PÉREZ, J., «Las tasas judiciales y la asistencia jurídica gratuita», cit., p. II.
} 
pueden servir para proteger a los justiciables frente a la excesiva inclinación a pleitear que pueden mostrar los abogados ${ }^{46}$.

En este sentido, resultan muy ilustrativas las conclusiones de MORA-SANGUINETTI, cuyos estudios econométricos de la litigiosidad en España muestran una correlación positiva, y la relación de causalidad, entre el número de abogados per capita y el número de litigios per capita $^{47}$, como se muestra en el siguiente gráfico:

\section{Litigiosidad per cápita y en porcentaje del PIB}

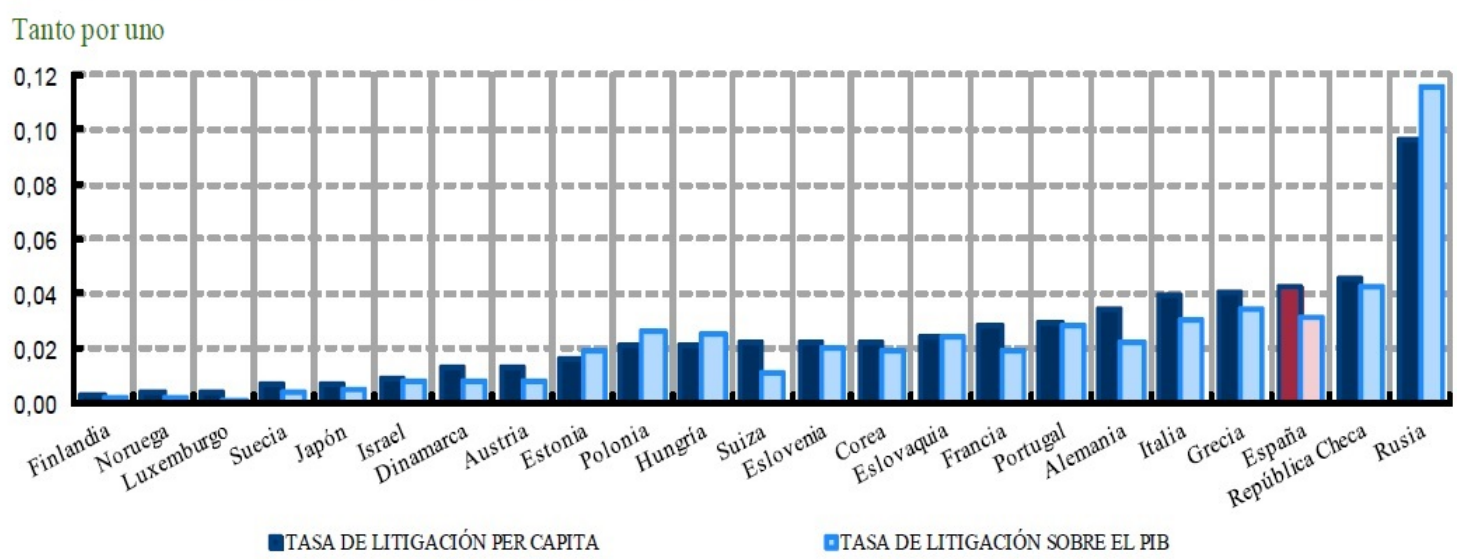

IV.2. Los beneficios de las tasas judiciales en el orden social

De acuerdo con el art. 63 de la Ley Reguladora de la Jurisdicción Social es requisito previo para la tramitación del proceso laboral el intento de conciliación o, en su caso, de mediación ante el servicio administrativo correspondiente o ante el Servicio Interconfederal de Mediación y Arbitraje o el Tribunal Laboral autonómico correspondiente, en función del ámbito territorial de conflicto laboral; conciliación o mediación laboral previa que se configuran como requisitos procesales para poder interponer demanda ante el órgano jurisdiccional laboral competente (arts. 80.3 y 8I LRJS).

Pues bien, es precisamente durante la tramitación de estos métodos extrajudiciales de resolución de conflictos laborales donde se pone más intensamente de manifiesto la necesidad de imponer tasas judiciales en el orden social.

En efecto, en el acto de conciliación o mediación previas al juicio laboral se observa perfectamente cómo el abogado que asesora al trabajador tiende a mantener sus pretensiones

\footnotetext{
${ }^{46}$ Así, DoméneCh Pascual, G., «Las tasas judiciales a juicio», cit., p. 2 I.

${ }^{47}$ Vid. Mora-Sanguinetti, J. S. y Garoupa, N. («Do lawyers induce litigation? Evidences from Spain, 200I20IO», International Review of Law and Economics, núm. 44, 2015, pp.29-4I; Mora SnaGuinetTi, J. S. y GómeZ Pomar, F., «Males de la Justicia: analizando los datos», InDret, núm. I, 20I4, pp. I-7; Mora SANGUinEtTI, J. S., «A characterization of the Judicial System in Spain: Analysis with Dormalism Indices», Economic Analysis of Law Review, Vol. I, núm. 2, 2010, pp. 210-240.
} 
iniciales en cuestiones de tan poca trascendencia jurídica como que las cantidades que se reclaman en concepto de indemnización por despido o por salarios no cobrados han sido mal calculadas, o cómo el abogado que asesora a la empresa prefiere dilatar el pago de las cantidades que privadamente reconoce adeudar ya salarios insatisfechos ya en concepto de indemnización por despido cuando así lo obligue el juez mediante sentencia.

La necesidad de imponer tasas judiciales en el orden social resulta evidente, además, cuando los mismos abogados que se negaron a recomendar al trabajador y/o al empresario a que llegaran a un acuerdo preprocesal en el acto de conciliación o mediación llegan, sin embargo, a un acuerdo extrajudicial en sede judicial.

Como tradicionalmente la interposición de demanda ante el órgano jurisdiccional social está exenta de tasa judicial, en la práctica se produce un abuso de derecho puesto que la pretensión resulta manifiestamente infundada, al haber quedado patente en la conciliación o mediación previa que o bien el trabajador o bien el empresario tenía razón en su pretensión, por lo que debieron haber solucionado el conflicto en vía preprocesal.

Por consiguiente, la inexistencia de tasas judiciales para interponer demanda laboral incentiva a los abogados a no llegar a un acuerdo en el acto de conciliación o mediación laboral previo, que resulta justo e incluso ventajoso para su defendido y pondría fin al conflicto laboral subyacente, para dilatarlo en vía jurisdiccional en el mejor de los casos para ganar tiempo para pagar lo que se debe, pero en muchos casos con la única finalidad de seguir engrosando la nómina de sus servicios profesionales. En sentido inverso, si se impone por ley el pago de tasas judiciales para interponer la demanda laboral los abogados del trabajador y de la empresa en conflicto tendrán un fuerte incentivo para llegar a acuerdos mutuamente ventajosos en el acto de conciliación o mediación previa, por lo que se evitará una práctica muy extendida de no discutir el conflicto laboral en vía preprocesal para llegar a un acuerdo extrajudicial ante el Letrado de la Administración de Justicia in limine litis, es decir cuando el proceso jurisdiccional ya ha comenzado, con los gastos que ello acarrea.

En consecuencia, la imposición de tasas judiciales para la interposición de demanda en toda clase de procesos declarativos y de ejecución de títulos ejecutivos extrajudiciales en el orden jurisdiccional social puede resultar cuádruplemente ventajoso para los trabajadores las empresas que se enfrente a un conflicto laboral. En primer lugar, se ahorrarán los costes en los que probablemente incurrirían de acudir a los tribunales y ser vencidos, costes que tal vez subestimen. En segundo lugar, verán reducidos los honorarios de sus abogados, al no tener éste el incentivo de prolongar indebidamente en vía jurisdiccional el conflicto laboral, e incluso suprimidos ya que no resulta preceptiva la intervención de abogado en los actos de conciliación o mediación previos al juicio laboral. En tercer, tanto si se resuelve el conflicto en vía preprocesal (así como si finalmente se ha de recurrir a la vía jurisdiccional social, puesto que la litigiosidad se verá también reducida), verán resuelto el conflicto laboral subyacente a sus pretensiones procesales en un plazo de tiempo más breve; algo que, aunque no resulte cuantificable, en muchas ocasiones será mucho más ventajoso para las partes en litigio. En cuarto y último lugar, la defensa de los derechos e intereses laborales de trabajadores y 
empresas en conciliación administrativa o en mediación autónoma ante el Servicio Interconfederal de Mediación y Arbitraje o ante los Tribunales Laborales autonómicos correspondientes, en función del ámbito territorial de conflicto laboral, es gratuito, por lo que todas las partes en un conflicto laboral van a poder una resolución fundada en derecho que resulta ejecutable a pesar de que no posean recursos financieros suficientes para litigar ${ }^{4}$.

En definitiva, una adecuada regulación de tasas judiciales que graven la interposición de la demanda en toda clase de procesos declarativos y de ejecución de títulos ejecutivos extrajudiciales en el orden jurisdiccional social proporciona a la importancia económica del pleito que permita la condena al pago de las costas al que litigara con temeridad, mala fe o abuso del derecho puede contribuir eficazmente a que disminuya la litigiosidad laboral, con la consiguiente reducción no sólo del gasto público a ella asociado sino también de la duración de los procesos laborales.

Pero además, la imposición de las tasas judiciales en el orden jurisdiccional laboral tendrá también un impacto positivo en la deontología profesional: los abogados que alcancen el más alto estándar moral son decisivo para evitar la litigiosidad laboral, como ha advertido el Presidente del Tribunal Europeo de Derecho Humanos al Colegio de Abogados de Belgrado ${ }^{49}$.

Por último, la exigencia de tasas judiciales para la interposición de demanda ante la jurisdicción laboral coadyuvaría, en fin, a que la conciliación, mediación y arbitraje laboral regulados en los arts. 63 a 68 de la Ley Reguladora de la Jurisdicción Social fueran herramientas realmente efectivas para la evitación del proceso laboral.

\section{Conclusiones}

La conclusión fundamental de lo aquí expuesto es que la pretendida «privatización de la justicia» de la que se habla en España para referirse a la introducción de las tasas judiciales como requisito para formular demanda no es tal, sino que, al contrario, se halla en línea con las corrientes actuales del Derecho procesal europeo y, más concretamente, con la práctica procesal británica.

Las reformas introducidas en el ordenamiento jurídico español para la introducción de las tasas judiciales están en línea con la práctica totalidad de los Estados miembros de la Unión

\footnotetext{
${ }^{48}$ En efecto, los procedimientos de conciliación y de mediación previos al proceso laboral está regidos por El principio de gratuidad, lo que implica que las partes en conflictos que acuden a ellos para tratar de solucionarlo como vía previa al proceso laboral no van a incurrir en coste alguno. De una parte, la conciliación administrativa se realiza ante funcionarios cuyos gastos se imputan al presupuesto general de la Administración pública competente. Por su parte, el art. 9 V Acuerdo sobre Solución Autónoma de Conflictos Laborales reconoce la gratuidad como principio rector del procedimiento de mediación ante el Servicio Interconfederal de Mediación y Arbitraje, en tanto que fundación del sector público estatal que cumple una función pública cuyos ingresos provienen de los convenios que tiene firmados con el Ministerio Empleo y Seguridad Social para financiar sus gastos. Idéntico principio de procedimiento se reconoce también en los acuerdos interconfederales de resolución de conflictos autonómicos para los procedimientos de conciliación-mediación ante los respectivos Tribunales Laborales autonómicos.
}

${ }^{49}$ Vid. GonZÁlez PÉREZ, J., «Las tasas judiciales y la asistencia jurídica gratuita», cit., p. IO. 
Europea, por lo que no puede achacarse al legislador español mala fe en su intento de equiparar nuestro sistema procesal civil al de los países de nuestro entorno.

A mayor abundamiento, puede concluirse que las causas que han llevado a la imposición de tasas judiciales son idénticas tanto en España como en el Reino Unido.

En efecto, la imposición de una tasa por el ejercicio de la potestad jurisdiccional resulta perfectamente asumible desde un punto de vista constitucional tanto en España como en el Reino Unido. De lo que se trata en ambos ordenamientos jurídicos es de establecer un modelo que se configure como un justo medio aristotélico en la tensión entre el derecho fundamental a la tutela judicial efectiva y el coste que comporta el ejercicio de la potestad jurisdiccional en su conjunto. En todo caso, el problema es diseñar un sistema de tasas judiciales que no subvierta el clásico principio de ULPIANO de que es preferible que un crimen quede impune a que un inocente sea condenado ${ }^{5 \circ}$. Como decía BENTHAM, el gobernante que contribuye a que la Justicia sea inaccesible es un encubridor de todo crimen; y es por ello que tanto el Gobierno español como el Gobierno inglés están trabajando en la actualidad para rediseñar sus respectivas tasas judiciales.

Ahora bien, mientras que el debate sobre las tasas judiciales en el Reino Unido gira en torno a su adecuada modulación para hacer más asequible el acceso a la justicia de los ciudadanos y empresas, ya que se asume que parte del coste de la Justicia lo han de sufragar los usuarios; sin embargo, en España existen muchas voces autorizadas tanto de la Academia como entre la Judicatura y la abogacía que siguen abogando por su completa supresión.

Se trata de opiniones apriorísticas o corporativas porque, tal y como se ha analizado, de la exigencia de pago de tasas judiciales para la interposición de la demanda en toda clase de procesos declarativos y de ejecución de títulos ejecutivos extrajudiciales en el orden jurisdiccional social se pueden extraer diferentes consecuencias positivas como: la reducción de la litigiosidad laboral, al evitarse muchas demandas infundadas o temerarias y los gastos del proceso a ellas asociadas, tal y como han destacado el Tribunal Europeo de Derechos Humanos y el Tribunal de Justicia de la Unión Europea; la potenciación de los procedimientos de conciliación y mediación previos que la Ley procesal laboral regula como obligatorios, precisamente para la evitación del proceso laboral, al igual que ocurre en el sistema procesal laboral inglés; y la reducción de los costes para trabajadores y empresas de la defensa de sus derechos laborales, ya que dichos procedimientos extrajudicial de solución de conflictos en España son gratuitos para las partes.

\footnotetext{
${ }^{50}$ «Satius esse impunitum relinqui facinus nocentis quam innocentem damnari», Digesto, De poenis, I,5.
} 